\title{
Optimality Theory in ESL Phonology: A Practice of Final Consonant Clusters from Vietnamese L1 Speakers
}

\section{Vi-Thong Nguyen}

Graduate Institute of Linguistics, National Chung Cheng University, Taiwan

Email: vithong1985@gmail.com

How to cite this paper: Nguyen, T. V. (2019). Optimality Theory in ESL Phonology: A Practice of Final Consonant Clusters from Vietnamese L1 Speakers. International Journal of Language Teaching and Education, 3(1), 20-27. https://doi.org/10.22437/ijolte.v3i1.6178

Accepted: March 14, 2019

Published: July 31, 2019

Copyright (C) 2019 International Journal of Language Teaching and Education

This work is licensed under the Creative Commons Attribution International License (CC BY 4.0). http://creativecommons.org/license s/by/4.0/

\begin{abstract}
The present study aims to adopt the Optimality Theory to investigate the strategies of pronouncing the final consonant clusters in English by a group of Vietnamese L1 speakers. Vietnamese is a language without the final consonant clusters; therefore, Vietnamese ESL learners tend to have different strategies to pronounce those. Seven Vietnamese graduate students were employed to record their word-list out-loud reading. Each of the consonants occurring in their pronunciation production was considered as one token to be analyzed. The result shows that Vietnamese ESL learners employ five different strategies to generate the final consonant clusters. After that, by adopting the Optimality Theory, this study provides both faithfulness constraints and markedness constraints for each strategy with the attempt to generalize the cases of the final consonant pronunciation of Vietnamese speakers. This study is significant for ESL teachers to understand how the Vietnamese language affects the ESL learners' final sound pronunciation.
\end{abstract}

\section{Subject Areas \\ Teaching Speaking}

\section{Keywords}

constraints, final consonant cluster, optimality theory, strategies, vietnamese ESL learners

\section{INTRODUCTION}

Second language acquisition is a process affected by simultaneous interaction of various factors such as the linguistic nature of the first language (L1), the structures of the target language (L2), universals of language acquisition, and the degree of exposure to L2 (Wiltshire, 2006). In Vietnam, English learned as a second language, which has never become an official language in this country. It is the fact that the English learning process of Vietnamese speakers can be strongly influenced by their L1, especially to novice learners (Nguyen \& Brouha, 1998). This phenomenon can be found in studies of English final consonant clusters generated by Vietnamese L1 speakers (Osburne, 1996; Nguyen \& Brouha, 1998). 
Nguyen and Brouha (1998), it confirmed that Vietnamese learners had difficulty in learning and maintaining the superficial voice contrast in word-final consonants in English. The discussed reason for this issue was that the English structure is more marked than the Vietnamese structure regarding these sounds. Moreover, $62 \%$ of substitutions were found in their data, which included devoicing, deletion, epenthesis, fricatization, Africanization, and unreleased. Meanwhile, Osburne (1996) focused on final cluster reduction in English by examining the case of a Vietnamese speaker. It was concluded in Osburne's study that the position of a reduced consonant can be widely predicted based on interaction with other rules, universal considerations, and L1 syllable structure.

The present study is an attempt to investigate the phenomenon of final consonant clusters in English produced by Vietnamese ESL learners with the application of Optimality Theory (OT), which has been recently instructed in Gussenhoven \& Jacobs (2017). As introduced in Boersma et al. (2000), OT was first developed by Prince and Smolensky in 1993, which was one of the prominent theories in the 1990s. It began a new constraint-based approach for various studies in phonology (e.g., Moira, 1993; Itô, 1995; Auger, 2001; Łubowicz, 2002; Beckman, 2003; Bermúdez-Otero, 2006; Cristia, 2018 ). As mentioned, this theory is a constraint-based approach, with which any surface form does not comply eliminated. It means that the form which the least violates the constraints is favored.

It should be noted that OT is considered a development of generative grammar, which shares its focus on the examination of universal principles, linguistic typology, and language acquisition. The theory also proposes two crucial features, which make up the answer to the question of why phonology is different across languages. First, languages are different in terms of their constraints' importance rankings. This ranking of the set of universal constraints is also known as the constraint hierarchy. Second, it is indicated that these constraints can be contradictory and be violated. In this case, the constraint with a higher ranking has priority. Therefore, by applying OT, this study is expected to indicate universal constraints and their rankings, which provides a new viewpoint to the issue of English final consonant clusters produced by Vietnamese ESL learners.

\subsection{Final consonant in Vietnamese.}

Vietnamese is a monosyllabic language, which means that each syllable is equivalent to a word. There are 11 vowels and 22 consonants in Vietnamese; many of them are found in the English system. Since this study only focuses on final consonant clusters, the distinction of the vowel systems and all of the consonantal systems between the two languages is not discussed. Table 1, extracted from Nguyen \& Brouha (1998), displays the differences between two final consonantal systems.

Table 1. Vietnamese final consonants (as compared to English consonantal system)

\begin{tabular}{cccc|ccc}
\hline \multicolumn{3}{c}{ Existing sounds } & \multicolumn{3}{c}{ Non-existing sounds } \\
\hline $\mathrm{p}$ & $\mathrm{t}$ & $\mathrm{k}$ & $\mathrm{n}$ & 0 & $\int$ & $\mathrm{t}$ \\
$\mathrm{m}$ & $\mathrm{n}$ & $\mathrm{g}$ & & $\partial$ & 3 & $\mathrm{~d} 3$ \\
\hline
\end{tabular}

It can be seen from Table 1 that the final consonants that exist in Vietnamese are single sounds. It is 
different from English in the point that final English sounds can be clusters, which never exists in Vietnamese. The non-existing sounds in Table 1 are from English; they do not exist in Vietnamese. However, this final consonant can be pronounced differently across dialects of Vietnamese. There are three main Vietnamese dialects: Northern, Central, and Southern. For one final consonant, there might be different variations depending on the dialect. With these differences between Vietnamese and English, it can be explained why Vietnamese ESL learners find it challenging to produce final consonant clusters.

\section{METHODOLOGY}

\subsection{Participants}

To serve the purpose of the research, seven participants were recruited. They are all Vietnamese L1 speakers, who are currently graduate students in a university in the central of Taiwan. They come from different dialects of Vietnamese. Their TOEIC band scores range from 500 to 650. They made voluntary contributions to the data collection process of this research. To avoid the Observer's Paradox (Labov, 1972), the participants were asked to read the word-list without being informed of the focus of final clusters. Even though the data were not entirely natural, they somehow minimized the situation in which the observation and information influenced participants' attention towards the final clusters.

\subsection{Instrument}

This study adopts the category for word-final clusters created by Wiltshire (2006). Table 2 shows the list of clusters used in the study and their tokens.

Table 2. Word-final consonants

\begin{tabular}{llc}
\hline \multicolumn{1}{c}{ Word-final Clusters } & \multicolumn{1}{c}{ Types } & Tokens (x7 participants) \\
\hline Nasal-stop & $\mathrm{mp}, \mathrm{nt}, \mathrm{nd}$, nd & 56 \\
Lateral-stop & $\mathrm{lt}, \mathrm{ld}, \mathrm{lp}$ & 42 \\
Lateral-nasal & $\mathrm{lm}$ & 14 \\
Fricative Stop & $\mathrm{st}, \mathrm{sk}, \mathrm{ft}$ & 42 \\
Stop-s & $\mathrm{ps}, \mathrm{ts}, \mathrm{bz}, \mathrm{dz}, \mathrm{gz}$ & 70 \\
Stop-Stop & $\mathrm{pt}, \mathrm{kt}$ & 28 \\
CC-s & $\mathrm{lts}, \mathrm{mps}, \mathrm{nts}, \mathrm{fts}, \mathrm{sks}, \mathrm{sts}, \mathrm{kts}$ & 126 \\
CC-Stop & $\mathrm{lpt}, \mathrm{kst} \quad 21$ \\
\hline & Total & $\mathbf{2 7}$ types \\
\hline
\end{tabular}

The participants were shown a list of words corresponding to types of clusters in Table 2 - each cluster gave the word containing that cluster as its final. Therefore, the list included 27 words. It should be noted that in order to calculate the exact number of tokens in data, each consonant in the cluster was counted as one token. There were seven participants; each participant read one word for 
one time. Therefore, with each consonant in a cluster, there were seven tokens made up. For example, for the group of Lateral-stop, there were three clusters, one of which contained two final consonants - two tokens. Therefore, each participant produced six tokens for this group, and seven participants made up a total number of 42 for this group of clusters. Participants were recorded reading the wordlist. In total, 399 tokens were being analyzed. The data were then coded, as shown in Appendix A.

\section{FINDINGS}

After coding and analyzing the data, the phenomenon of producing English final consonant clusters reveals five main strategies employed by the Vietnamese ESL learners to have an ease in their pronunciation: deletion, voicing, devoicing, ə-insertion, and featural change. Table 3 provides the number of tokens for each strategy in each group of clusters. It should be noted here that the percentage provided next to the number of tokens is calculated within each group of the cluster, not the percentage over the total number of tokens.

Table 3. Strategies employed by ESL learners

\begin{tabular}{lllllllllll}
\hline & \multicolumn{2}{c}{ Deletion } & \multicolumn{3}{c}{ Voicing } & \multicolumn{3}{c}{ Devoicing } & \multicolumn{3}{c}{ ə-insertion } & \multicolumn{2}{c}{ Feature-changing } \\
& $\mathrm{N}$ & $\%$ & $\mathrm{~N}$ & $\%$ & $\mathrm{~N}$ & $\%$ & $\mathrm{~N}$ & $\%$ & $\mathrm{~N}$ & $\%$ \\
\hline Nasal-stop (56) & 2 & 3.6 & 2 & 3.6 & 3 & 5.4 & 1 & 1.8 & 2 & 3.6 \\
Lateral-stop (42) & 19 & 45.2 & 1 & 2.4 & 0 & 0.0 & 0 & 0.0 & 1 & 2.4 \\
Lateral-nasal (14) & 7 & 50.0 & 0 & 0.0 & 0 & 0.0 & 0 & 0.0 & 1 & 7.1 \\
Fricative Stop (42) & 4 & 9.5 & 5 & 11.9 & 0 & 0.0 & 3 & 7.1 & 7 & 16.7 \\
Stop-s (70) & 13 & 18.6 & 3 & 4.3 & 14 & 20.0 & 0 & 0.0 & 5 & 7.1 \\
stop-stop (28) & 9 & 32.1 & 3 & 10.7 & 0 & 0.0 & 2 & 7.1 & 1 & 3.6 \\
CC-s (126) & 53 & 42.1 & 1 & 0.8 & 0 & 0.0 & 1 & 0.8 & 3 & 2.4 \\
CC-stop (21) & 10 & 47.6 & 0 & 0.0 & 0 & 0.0 & 0 & 0.0 & 1 & 4.8 \\
\hline 399 & 117 & 29.3 & $\mathbf{1 5}$ & $\mathbf{3 . 8}$ & $\mathbf{1 7}$ & $\mathbf{4 . 2}$ & $\mathbf{7}$ & $\mathbf{1 . 7}$ & $\mathbf{2 1}$ & $\mathbf{5 . 2}$ \\
\hline
\end{tabular}

As shown in Table 3, the most favored strategy employed by Vietnamese ESL learners is the deletion of a consonant(s) in the final cluster. Roughly $30 \%$ of tokens found a show this strategy. The table also shows that the group that has the most significant number of consonantal deletion is Lateral-nasal with $50 \%$ of its tokens found with deletion. As can be seen in Appendix A, nearly all of the lateral sounds /l/ in this group is deleted. Another evidence for lateral deletion is the percentage shown in Lateral-stop group. As Appendix A shows, roughly all of the deletion in this group is from the lateral sound.

Other groups that show the high percentage of deletion are CC-stop with $47.6 \%$ and CC-s with 42.1\%. As can be observed in Appendix A, almost no three-consonant cluster is pronounced without at-least-one-consonant deletion. It can also be seen in Table 3 that deletion rarely occurs in groups of Nasal-stop (3.6\%) and Fricative-stop (9.5\%).

The second-largest strategy favored by Vietnamese ESL learners is featural changing even though it makes up 5.2\% of the total tokens only. Table 3 indicates that the group with the highest rate of featural change is Fricative-stop (16.7\%). As can be seen in Appendix A, most of the cases of featural change derive from the alveolar $/ \mathrm{t} /$ and postalveolar $/ \mathrm{J} /$. The alveolar $/ \mathrm{t} /$ tends to be 
changed into dental stop / $\mathrm{t} /$ while post alveolar $/ \mathrm{J} /$ is changed into alveolar /s/. As observed in Appendix A, most of the cases of this strategy occurring in other groups of cthe luster also derive from these two sounds. Devoicing is also a strategy that Vietnamese ESL learners choose to deal with the final consonant cluster (4.2\%). It is noticeable that 14 out of 17 cases of this strategy comes from Stop-s group. As Appendix A shows, almost all of the cases of devoicing are from the voiced alveolar /z/, which is devoiced into voiceless alveolar /s/. Voicing also occurs as one of the strategies. Even though the number is small, it shows a consistent trend that only two voiceless sounds / $\mathrm{t} /$ and /b/ are voiced into $/ \mathrm{d} /$ and $/ \mathrm{p} /$, respectively. $ə$-insertion is a process found in the data when the word ending with a stop as $/ \mathrm{t} /, / \mathrm{t} /$, or $/ \mathrm{k} /$. Even though the number of evidence for this strategy is small, it shows that the phenomenon does exist in reality.

\subsection{Rankings in $0 \mathrm{~T}$}

This section aims to propose possible constraints under which the final consonant cluster producing process are controlled. First, an attempt to present a set of faithfulness constraints with their ranking is proposed for all the five strategies stated in Section 4. Then, markedness constraints with ranking are explicitly proposed for each type of strategy.

Faithfulness constraints

To assure the identicalness in terms of underlying and lexical form between the input and output, these faithfulness constraints are proposed.

\section{Faithfulness}

MAX-IO: input must be maximally represented in the output (no deletion)

DEP-IO: output must be "dependent" on the input (no insertion)

IDENT(F): each feature in input and output is identical (no featural change)

IDENT(V): each voice in input and output is identical (no voice change)

These constraints are expected to provide a universal for the underlying form of the final consonant clusters. As found in Section 3, a high number of cluster bear the deletion process; therefore, MAX-IO is a constraint to prevent speakers from deletion. In the analysis, some cases with ə-insertion were found. DEP-IO is proposed to control this process. Moreover, Vietnamese ESL learners tend to change the consonant's feature and voice; therefore, IDENT(F) and IDENT(V) constraints are given to reflect the phenomenon.

According to the results in Section 3, it seems that the cluster pronunciation tends to be less unusual when there is consonantal deletion. Meanwhile, featural and voice changes less frequently occur in the data. Schwa-insertion is the least favored strategy by the speakers. Therefore, this result may imply the ranking for the OT in terms of faithfulness constraints as follow. 
(1) DEP-IO $>>\{$ IDENT(V), IDENT(F) $\}>>$ MAX-IO

\begin{tabular}{lllll} 
koments & DEP-IO & IDENT(V) & IDENT(F) & MAX-IO \\
\hline komentz & & $*$ & $*$ \\
\hline komens & & & \\
\hline komentsə & $*$ & & \\
\hline koment & & $*$ & \\
\hline
\end{tabular}

The example above shows how OT works in the data. The example is also from the data of this study.

Markedness constraints

In terms of universal grammar, markedness is encoded based on the type of strategy.

\subsection{Consonantal deletion}

According to the result in Section 3, the deletion is consistently from the lateral $/ \mathrm{l} /$, while the deletion in other groups is entirely arbitrary, mainly due to the complexity of the cluster, not the feature of the consonant. Therefore, two markedness constraints are proposed for deletion.

MINCODA: the coda contains minimally one consonant

CODALAT: the coda must not contain lateral approximant

Regarding ranking in OT, it can be seen that MINCODA is more important than faithfulness since it may decide the optimality of the candidate. In other words, a candidate can be unnatural if it has no coda for a final cluster. Meanwhile, CODALAT is not that important, so it should be ranked lower than faithfulness.

\begin{tabular}{|c|c|c|c|c|c|c|}
\hline help & MINCODA & DEP-IO & IDENT(V) & IDENT(F) & MAX-IO & CODALAT \\
\hline hel & & & & & * & $*$ \\
\hline$\Phi$ & & & & & * & \\
\hline helpə & & * & & & & * \\
\hline he & * & & & & & \\
\hline
\end{tabular}

\subsection{Featural and voice changing}

As observed in Appendix A, it can be seen that the sound that is chosen to substitute the original one should remain the same manner of articulation. For example, /t/ and /t/ are both stop; /s/ and /S/ are both fricative. This grammar also applies for voicing and devoicing changing process. Therefore, the constraint for this strategy is proposed as follow. 
REARTM: the consonant changed in terms of either voice or feature must remain its manner of articulation.

When putting this constraint in the ranking, it can be seen that this is a critical constraint to determine the optimality of the candidate. Therefore, it is located after DEP-IO in the set of constraints.

\begin{tabular}{|c|c|c|c|c|c|c|c|c|}
\hline $\operatorname{dog} z$ & & $\begin{array}{l}\text { MIN } \\
\text { CODA }\end{array}$ & DEP-IO & REARTM & IDENT(V) & IDENT(F) & MAX-IO & CODALAT \\
\hline dogr & & & & $*$ & & * & & \\
\hline$\Phi$ & dogs & & & & & $*$ & & \\
\hline do & & $*$ & & & & & & \\
\hline dogzo & & & $*$ & & & & & \\
\hline
\end{tabular}

\subsection{Schwa insertion}

As analyzed in Section 3, schwa is inserted only after some final stop consonants. Therefore, it decides to change the faithfulness constraint DEP-IO into DEP(-ə) with a markedness constraint FINSTOP.

DEP-(-ə): output must be "dependent" on the input (no insertion except $ə$ )

FINSTOP: the coda must end with a stop (excluding the vowel following).

DEP-(-ə) still remains its importance, so it still remains the position of high ranking. FINSTOP is not that important since it is only to control the schwa insertion; therefore, it stands at the same ranking with CODALAT.

(4) MINCODA $>>$ DEP-(-ə) $>>$ REARTM $>>\{$ IDENT(V), IDENT(F) $\}>>$ MAX-IO $>>\{$ CODALAT, FINSTOP\}

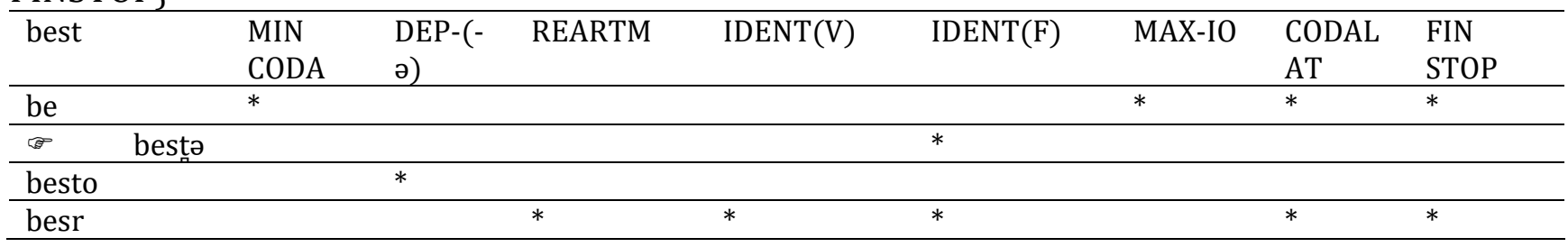

\section{CONCLUSION}

This study is an attempt to apply OT in second language phonology. By examining the phenomenon of producing English final consonant clusters by Vietnamese ESL learners, the study has indicated five strategies that the learners adopt to deal with the difference with their L1 in terms of final consonant clusters: deletion, voicing, devoicing, ə-insertion, and featural change. Besides, the study has attempted to propose a universal set of constraints for this phonological phenomenon, which is expected to help judge phonological candidates. This study is a reference for ESL teachers who are teaching English to Vietnamese speakers to understand their phenomenon of producing the final sounds.

It should be admitted that no more participants could be recruited for the project, which may affect the generalization of the claim. However, this study can be considered a pilot study for largerscaled research in future, which is expected to have more substantial pedagogical contributions to ESL/EFL in the Vietnamese context. 


\section{References}

[1] Auger, J. (2001). Phonological variation and Optimality Theory: Evidence from word-initial vowel epenthesis in Vimeu Picard. Language variation and change, 13(3), 253-303.

[2] Beckman, J. N. (2013). Positional faithfulness: an Optimality Theoretic treatment of phonological asymmetries. Routledge.

[3] Bermúdez-Otero, R. (2006). Phonological change in optimality theory. Encyclopedia of language and linguistics, 9, 497-505.

[4] Boersma, P., Dekkers, J., \& Weijer, J. v. d. (2000). Introduction - Optimality Theory: phonology, syntax, and acquisition. In J. Dekkers, F. v. d. Leeuw \& J.v. d. Weijer (Eds.), Optimality Theory: phonology, syntax, and acquisition: Oxford University Press.

[5] Cristia, A. (2018). Can infants learn phonology in the lab? A meta-analytic answer. Cognition, 170, 312-327.

[6] Gussenhoven, C., \& Jacobs, H. (2017). Understanding phonology (fourth edition). London and New York: Routledge.

[7] Itô, J., Mester, A., \& Padgett, J. (1995). Licensing and underspecification in Optimality Theory. Linguistic inquiry, 26(4), 571-613.

[8] Labov, W. (1972). Sociolinguistic patterns (No. 4). University of Pennsylvania Press.

[9] Łubowicz, A. (2002). Derived environment effects in Optimality Theory. Lingua, 112(4), 243-280.

[10] Nguyen, A., \& Brouha, C. (1998). The production of word final consonants in English by L1 speakers of Vietnamese. Working papers in Linguistics, 5, 73-94.

[11] Osburne, A. G. (1996). Final Cluster Reduction in English L2 Speech: A Case Study of a Vietnamese Speaker. Applied Linguistics, 17(2), 164-181.

[12] Prince, A., \& Smolensky, P. (1993/2008). Optimality Theory: Constraint interaction in generative grammar. John Wiley \& Sons.

[13] Moira, Y. (1993). Cantonese loanword phonology and Optimality Theory. Journal of East Asian Linguistics, 2(3), 261-291.

[14] Wiltshire, C. R. (2006). Word-final consonant and cluster acquisition in Indian English(es). In 30th Boston University Conference on Language Development (pp. 1-10). 